\title{
SALARY CAP MODEL - INFLUENCE OF SPORTS LEAGUES COMPETITIVENESS - NATIONAL BASKETBALL ASSOCIATION VS NATIONAL HOCKEY LEAGUE IN NORTH AMERICA
}

\author{
Daniel Nicolae M $\breve{A I T A^{a}} \breve{a}^{*}$, Alexandra-Irina PADUREAN (BADEA), \\ Claudiu CREȚU ${ }^{c}$, Vasile APOSTOL ${ }^{d}$ \\ ${ }^{a, b, c, d}$ Bucharest University of Economic Studies, Romania
}

\begin{abstract}
Professional sports in North America has become, in recent years, a billion-dollar industry, where players are slowly becoming the industry's biggest assets. Through players, US national leagues have managed to grow in recent years by about $60 \%$, but with this increase, player salaries have begun to become more competitive in the market, managing to reach impressive amounts in a short period of time. This research seeks to investigate the direct relationship between two models of the salary cap - hard cap salary and soft cap salary and the direct relationship with the success of teams in American national leagues in recent seasons. Also based on this study, the aim is to compare the leagues that use a hard cap salary model (NHL), with the leagues that use a soft salary model (NBA), and which of the two are more competitive from a professional and economic point of view.
\end{abstract}

KEYWORDS: professional sports, salary cap, competitive level, economic competitiveness

DOI: 10.24818/IMC/2021/01.18

\section{INTRODUCTION}

For more than two decades, in professional and international sports there have been a series of salary limits, which help, or not the teams, to remain competitive in sports but also economically, for a longer period of time. But, throughout this period, these salary limits have gone through various changes and ideas, which have affected a number of franchises, positively but especially negatively. The salary limits were implemented within the professional sports leagues, in order to be able to establish the financial position of each team, but also to be able to maintain a balance between the best-ranked team but also the lowest-ranked team in that league. This system has also been implemented in order to stop the influences between different teams and players, which are linked through a series of marketing contracts. (Dietl, Franck, Lang \& Rathke, 2012)

The restrictions of a salary cap have forced all teams to focus on their financial side and try to build a highly optimized management system in order to achieve a remarkable performance during their existence. Another very important aspect, which these salary restrictions introduced, was the management of the amounts so that the most important assets of the companies, namely the players, can remain satisfied and competitive at the same time. A franchise player can be the reason why a team can be competitive in the league it belongs to or the reason why it struggles at the bottom of the standings. All these franchise players can sink all the financial and managerial hopes of the companies behind the teams. All of this is happening because, in recent years, the professional sports industry, at least in North America, has seen a very large increase in popularity of about $60 \%$. In order to be able to make a correct distinction between the teams with higher visibility and the smaller ones, with lower visibility, and automatically with a lack of notoriety in the public space, the national leagues had to introduce this differentiating aspect.

"Corresponding author. E-mail address: daniel.n.maita@ gmail.com 
In order to make a correct distinction between national leagues, at least in North America, three types of salary caps have been built, which do not affect the team management system, as follows: the hard salary cap, soft salary cap, and a voluntary salary cap. This type of salary cap is used in almost all sports around the world, with different variations depending on league preferences and how local competitiveness is managed.

Because, the main objective of an organization within a professional sports league, regardless of the category it belongs to, is the way to stay at the top and win as many games as possible. Based on these considerations, economic growth can be exponential. In order to be able to stay at the top, an organization needs the best players that it can bring from the free market, or that it can train in its own academy. But still, what is the right way for an organization to maintain its economic and professional competitiveness in a world where change is very fast? Some experts say that an organization must primarily satisfy the public because they are the ones who bring revenue to franchises and it depends on them if they want to see an organization that has aspirations for the title every year or simply want to pursue a favorite team. This paper explores the success of organizations in both situations, presenting two different models of salary capping. The current study seeks to identify the answer to the following question: Is a single wage cap model needed for all leagues in North America to be competitive? Or to keep an industry like this competitive, is it necessary to keep the current wage ceilings? (Larsen, Fenn, \& Spenner, 2006).

North America is one of the continents where all professional sports leagues use a salary cap. The four major leagues that use this salary cap are National Hockey League (NHL), National Basketball Association (NBA), National Football League (NFL), and Major League Baseball (MLB). All these organizations are part of either the professional leagues in the USA or in Canada and have as component 30 or 32 teams with one general objective - to win the competition, regardless of its format. Considering only the four leagues we talked about a little earlier, the NHL and NFL are the only ones with a hard salary cap. On the other hand, MLB and NBA use a soft salary cap, which allows them to be much more flexible in terms of salaries of professional players, allowing them to negotiate their benefits much better and consciously, taking into account different situations, as the economic development of the organizations to which they belong. In addition to this soft salary cap, the two professional leagues also use, at the same time, a luxury tax, which allows organizations to exceed the cap within the applicable rules of that year, paying for this excess an additional fine, set by staff associations. These salary caps have increased the competitive level of the four leagues we were talking about, and as a result, the presence of spectators has increased by about $85 \%$ over the last 10 years. All of these leagues had combined revenue of about $\$ 44$ billion, with the NFL having the largest financial share, about $35 \%$ of the total value. For this paper, I chose to focus on two of the four major professional leagues, namely the NHL and NBA. In short, this paper performs a comparative analysis between the two direct pay systems and how to pay impacts the competitiveness of the two associations.

\section{LITERATUR REVIEW}

Although a multitude of sports has been practiced in the United States over the decades, with a multitude of rules, the oldest sport on the North American continent, based largely on a structured system, is hockey. Hockey introduced the first national professional league concept in the USA, giving birth to the first national league with nine teams, also called the National League of Professional Hockey Clubs (NL), founded in 1876. In 1876, the national hockey league faced a major flaw in which the owners of the then organizations had a complete monopsy on the services of the players and had complete decision-making power, the association has no control over salaries, payment methods, thus providing a system without competitiveness, both economic and professional. Because there is a big discrepancy between financially powerful organizations and those at the bottom of the rankings, at that time a series of rival leagues were formed, where only those who met certain 
pre-established economic criteria participated. (Vrooman, 2000). Starting with 1879, in order to put an end to this economic standard, but also to improve the balance sheets of the owners of organizations, NL introduced a new rule, also called the "reserve clause". In short, the new rule assumes that all players were tied to the team that acquired the initial contracting rights (Dietl, Lang $\&$ Werner, 2010). As a result, the owners now had additional monopsony power over the players and their salaries fell sharply. However, although at first, this new rule seemed quite controversial, it proved to be the main pawn in establishing new associations over time and in the exponential increase in the salary paid to players.

In order to understand the importance and relevance of capping salaries in professional sports, there are a number of additional factors that must be taken into account. Salary caps in professional sports require a number of major factors, in order to balance competitiveness in the league but also to provide organizations with an equal amount of capital, to spend on players' salaries, in order to impose economic balance and global costs of organizations. The salary cap represents in specialized terms, the limit placed on a salary paid to employees and applied by the government or another organization. In sports industries, especially in North America, the salary cap is negotiated by associations with players and the league's leadership group in order to reach a level that satisfies both parties. These salary limits are in fact designed to have an upper and lower limit, which can determine the total amount of expenses for the salaries of an organization. If for the upper limit, it is logical why most organizations try to get a margin as high as possible, when we refer to the lower limit, there are several aspects that we must consider. First of all, from an economic point of view, an organization can establish the way of the season according to the financial needs of the team. (Cousens \& Slack, 2005). The more the identification of viable economic solutions for organizations and associations, the more likely it is that a team will be more competitive and try to become an important pawn in this industry. Secondly, this lower limit was invented so that a certain organization, which is in an economic impasse, avoids losing intentionally, in order to obtain economic advantages from the association and to keep the league competitive.

All these elements are realized so that both the organizations and the associations become part of a managerial and economic development process, which can directly help the planning and identification of the new solutions for the future. (Thurman, 2016). Another important factor in defining the economic power of an organization is the size of the club market. Teams located in small cities, which do not belong to a metropolitan area, tend to find more difficultto stay in the market compared with teams located in large, rich cities. First of all, big cities tend to attract more and more fans and manage to fill the arenas much easier at much higher prices. Secondly, a lot of players are trying to reach a much bigger market, with potential, to gain visibility and to be able to get a series of marketing and advertising contracts. In order to maintain stability and to reduce this phenomenon, salary caps were invented. Also, another advantage of the salary cap is the economic stability that the organization establishes when the salary limits decrease the foam of the self-destruction contract.

In short, the salary cap is an agreement on how much an organization can spend for its players and is implemented primarily to maintain the balance and increased competitiveness of the association. When salary caps are used, each organization generally has the same economic conditions and develops the opportunity to have the same amount of talent as all teams in the association. This salary cap brings more economic benefits for organizations because spectators are directly interested in a more balanced competition, where there are real chances for each organization if it knows how to manage very well the resources it benefits from. Based on a study conducted by several economic experts, it was identified that if this salary limit disappears, metropolitan teams could register all the star players in the league and could always be favorites to win national titles, every year, given that these organizations have much larger financial resources than small-volume organizations. This would drastically lower the level of fan interest in professional national leagues, and economic competitiveness would no longer exist. (Kahn, 2000) 
At the beginning of the $20^{\text {th }}$ century, a major impact on the salary development of professional National Hockey League players was the development of new integrated management systems that a large number of organizations decided to use. However, dissatisfaction arose among the players due to the emergence of a new rival league, which managed to attract some famous NHL players each year, attracting them with salaries of about $80 \%$. The new league, also called the Federal League, managed to attract in just under eight years, about $37 \%$ of the top players, enticing them with higher salaries and certainly a long career but also with extra benefits which the official league could not sustain. All of these things changed when the Great Depression hit North America. Salaries have dwindled, bonuses promised to big players have come to a standstill, with the Federal League ending immediately due to the poor managerial organization it has shown (Booth, 2007).

As in hockey, basketball has also gone through a dark era of player salaries, due to the reserve clause. In short, the players are drafted by the teams that are part of the national basketball association (NBA) which, after the draft, have exclusivity in terms of the player's rights until the end of his career.(Ajilore \& Hendrickson, 2002). All these elements lead to a single result, namely, the deficient way of managing the entire salary process that allows increasing competitiveness in the economic but also professional field. The reserve clause had a shorter existence in the national basketball association because some local investors at that time decided to financially support the organizations that were part of the entire process of economic development. They were in metropolitan areas, with huge potential for development, they soon benefited from financial support from some investors, thus managing to dictate the new national salary code for the NBA. With the elimination of this reserve clause, there began to be a series of discussions between owners, players, and the board of directors of the association, in order to cap salaries, to reach a high competitiveness threshold (Lipasti, 2015). Based on the MLB model, the NBA decided that capping should be based on logical rules, but with the direct involvement of the owners who had an important say in establishing the association's new management model. In light of the discussions that took place, the NBA became the first major league in North America to succeed in imposing the first collective bargaining agreement for players and support staff. The collective bargaining agreement aimed to establish moderate salaries, which means that a soft salary cap will exist, that involves the possibility of exceeding the base ceiling set by the league provided that the owners pay players part of the negotiated contract, and a luxury tax to the association, if it exceeds an amount of $90 \%$ of the full contract value. Luxury tax represents an additional tax that the organizations, mainly their owners, pay when the team's salary exceeds the limit of the fixed ceiling established by the respective league in which the organization carries out its activity. (Opperman, 2017). This luxury tax was essentially designed to prevent the growth of salaries to the liking of the owners and to prevent the organization from signing the top players in that league, thus maintaining the competitive league. The money obtained from this luxury tax is then distributed to the financially weaker organizations to create a much better financial relationship between the organizations. In order to understand how the NBA works, teams that exceed the maximum limit must pay the league a 100\% tax for every dollar that their salary exceeds the tax level. (Shorin, 2017).

\section{METHODOLOGY}

This research investigates the NHL and NBA's payroll system, highlighting an economic comparison between how they remain competitive in the long run, depending on how wages are capped. The reason this type of comparison was chosen is that though one has a hard cap and the other a soft cap they are similar in the fact that they have a specific cap that teams have to follow and to see which salary cap model is more competitive in order to maintain the professional competitiveness. This paper investigates the matches played in the regular season together with the playoffs of the analyzed year. This analysis is necessary to fully understand whether one salary-cap model is more competitive than the other from an economic, professional, and social point of view. In order to be able to perform this analysis in a real system, it was necessary to include both the regular season matches and the 
playoff matches. Supposing have a clear vision of the result, it was decided to analyze at least 13 seasons, starting with 2006 until 2019, inclusive.

The reason for the specific timespan was made because in the 2006 season, the NHL professional league did not have an economic model of salary capping and for this reason the previous data become irrelevant. Otherwise, in both leagues, the playoff system is the same. All playoff rounds are a best of seven-game series where the first team winning four games against the opposing team advances to the next round. In all the rounds the higher-seeded team has a home-court advantage, as they get to play one more game on the home court than the opposing team. This system gives a competitive advantage to the team's players and also brings economic growth to team owners.

In this part of the research, the results of the collected data will be shown and analyzed. The empirical part will start with a descriptive analysis between the playoffs system of the two leagues and the champions and finals appearances in both leagues, based on the salary caps. Secondly, the regular season will be studied and it will provide some information about how the salary cap will affect the team progress in the actual standings. Ultimately, simple regressions will be used to illustrate the collected information and to establish the future subjects of analysis. Furthermore, the research will try to answer that it will be possible to adopt a hard salary cap in the NBA like NHL, and what would be the results obtained.

\section{EMPIRICAL ANALYSIS}

\subsection{Descriptive analysis}

To make an empirical analysis of the entire process of economic development of associations, it is first necessary to analyze the differences between hard salary cap and soft salary cap and to see which of the two economic elements can produce, in the medium and long term, a competitive association. A hard salary cap means that all organizations in the analyzed association have a strict limit in terms of budget and how they can spend their money on players' salaries in a season. Among the top leagues in North America, two of them use hard salary caps, namely the NHL and NFL. Making a comparison between the two top leagues, the NHL uses a strictly hard cap, in which no team can exceed this maximum salary cap, regardless of the economic situation in the market. On the other hand, in the NFL the same rule is observed only that along the way an exception to the rule was approved. In order for all registered new contracts to be approved, a meeting with the professional league office is needed for extra approval. During this meeting, all contracts are analyzed, and those that lead to exceeding the hard salary cap in the analyzed year are rejected. An advantage that this new rule has, if an organization's salary is below the ceiling, is to report the difference between the maximum salary limit and their annual budget.

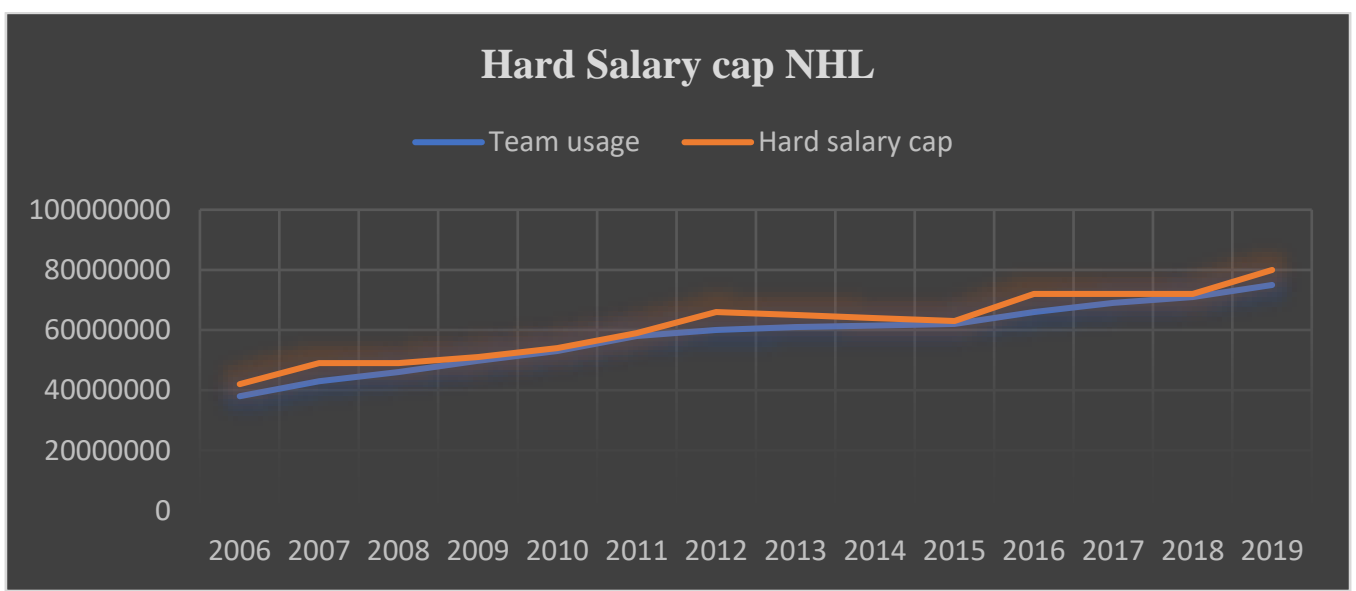

Figure 1. Usage of salary cap compared to the salary cap in the NHL

Source: adapted from Shorin (2017), p.22 
From figure 1 it is visible that in the leagues with hard salary cap the use of the salary ceiling is always below the allowed limit. Never, in the last 13 years analyzed, has there been a period where the budget used by a team to exceed the hard salary cap. This type of salary cap is a positive example for all organizations in North America that fail to cope with improving competitiveness and profitability overall. For example, for the 2012-2013 season, the salary cap was $\$ 66,000,000$, and the team with the lowest salary cap, the Ottawa Senators, managed to save about $38 \%$ of the budget, given that in that season the organization was in a rebuilding mode. This stage is a reconstruction phase that any franchise is ready to tackle when they restore their long-term goals. In order to remain competitive in an association with a lot of economic power, each organization chooses to go through a reconstruction phase that offers them different economic and managerial perspectives related to the new requirements in the sports market.

On the other hand, at the other end of the analysis is the national basketball association that uses a combination of the soft salary cap and luxury tax. Although this payroll policy is totally different from the NHL, the NBA has decided that from a competitive and economic point of view, this rule of soft salary cap is the most suitable for them. Starting with the 2013-2014 season, the NBA reduced the salary cap to $\$ 63$ million for each team, the latter being able to exceed this cap provided they pay a luxury tax for each dollar exceeded.

To provide salary flexibility, a number of ceiling exceptions have been introduced in the NBA for different categories of players: The Larry Bird exception, Mid-Level Exception, and Rookie Exception. The Larry Bird exception is the most used of them and offers the organization the right to register a player above the salary limit, only if he has already played for them at least 3 years in advance. In addition to these exceptions, there are many others with a much higher degree of complexity that vary depending on the time and economic position of the organization. Most of these exceptions offer organizations the opportunity to exceed the salary limit, thus managing to maintain the association at a level of interest for supporters.

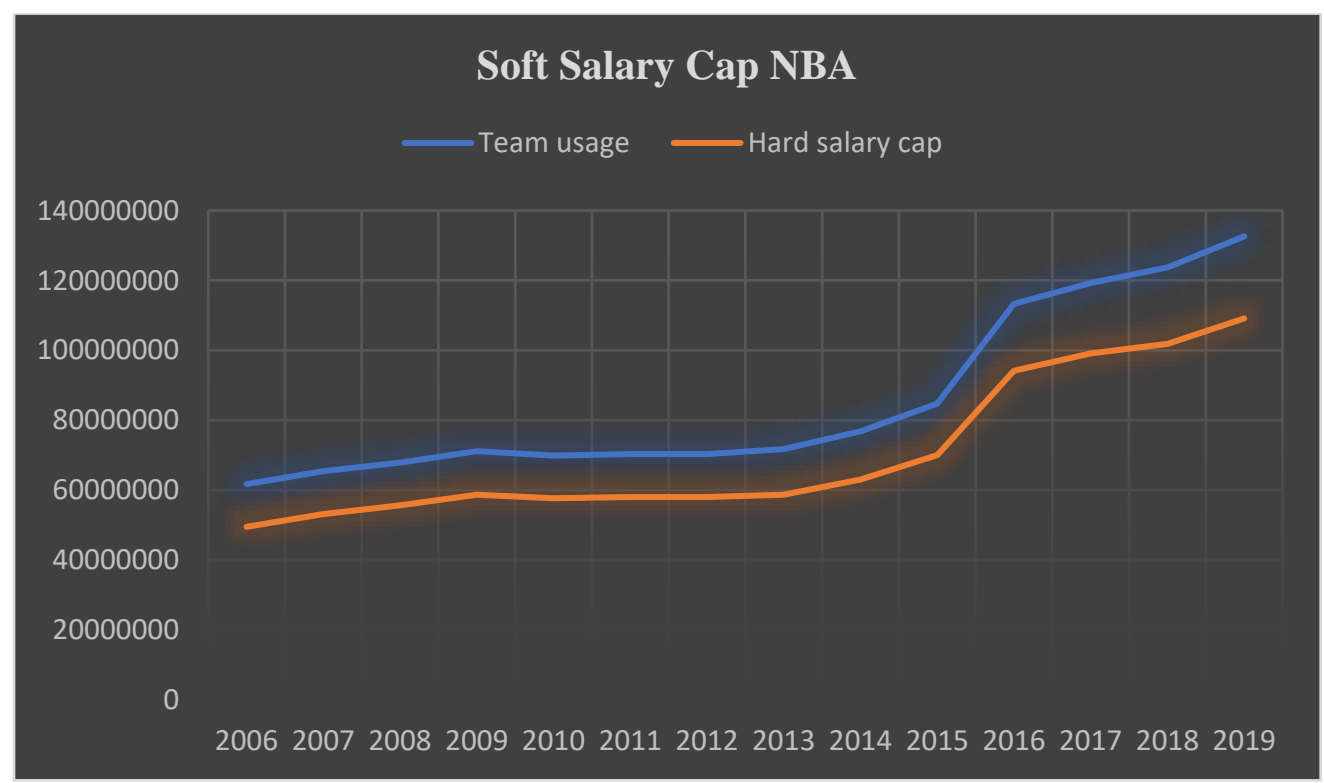

Figure 2. The usage of salary in Soft salary cap model in NBA

Source: adapted from Shorin (2017), p.30

Figure 2 shows that NBA organizations use an average of more than \$ 8-10 million per season to pay players' salaries. From the beginning of the 2006 season until the last analyzed season, 2019-2020, all 30 organizations part of the association exceeded the salary head by more than $135 \%$. Although since 2015, the difference between the usage salary cap and the current salary cap has decreased, the organizations have not been able to align and get under the cap. All these cap increases are largely 
due to the increased popularity of the sport in the analyzed period but also to an image agreement negotiated between the association and NBPA of America. And the main beneficiaries of these salary increases are also the players, who registered salary increases of over $150 \%$.

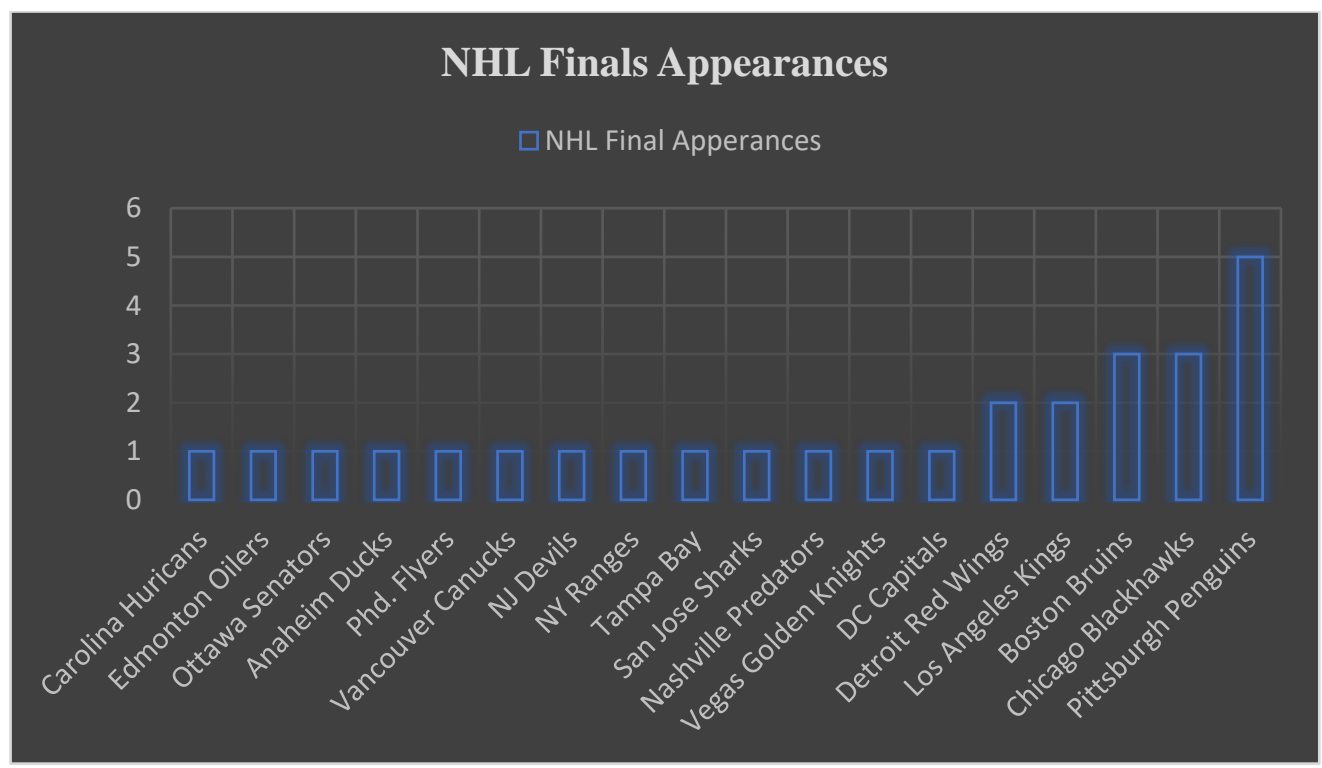

Figure 3. NHL Finals Appearances teams 2006-2019

Source: authors

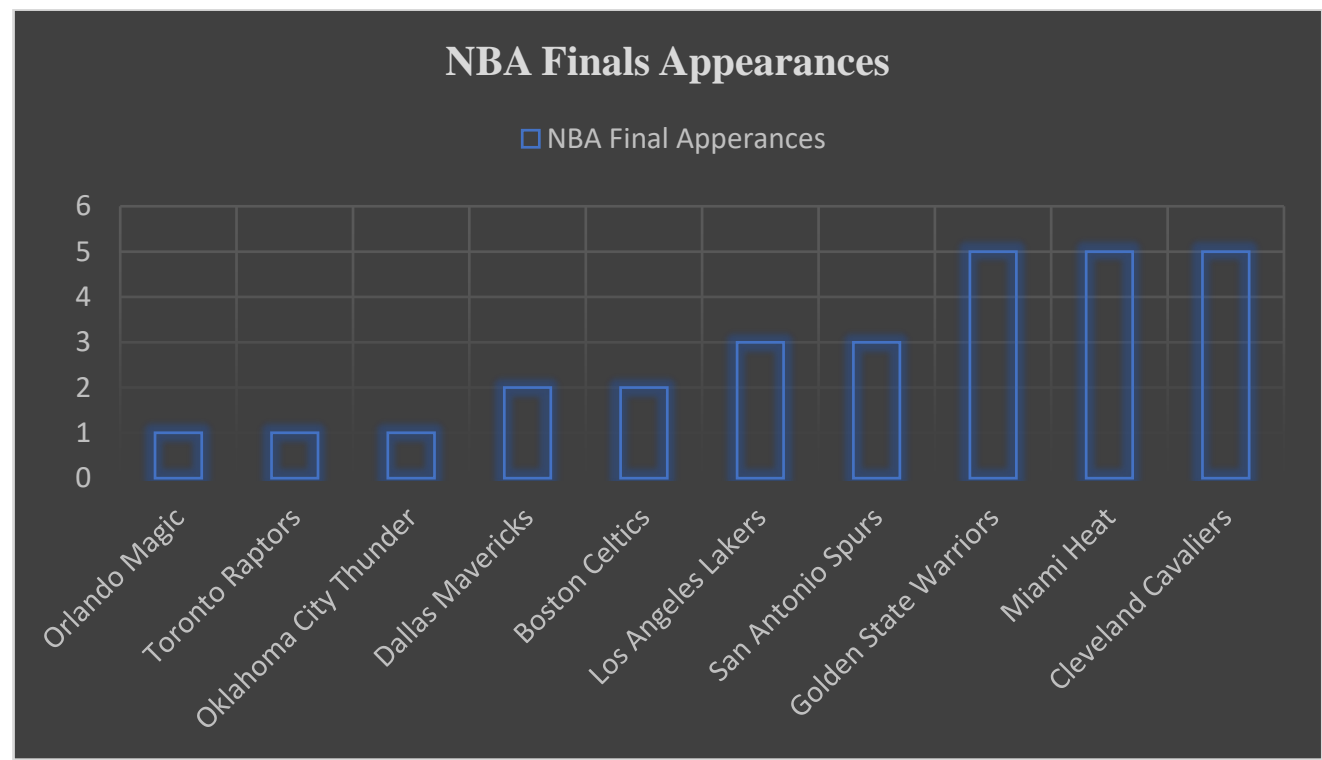

Figure 4. NBA Finals Appearances teams 2006-2019

Source: authors

Comparing figure 3 and figure 4, where the teams reached the final, we can see a difference in percentage between the two professional leagues. In the NBA, only 10 teams managed to reach the finals in the last 13 years, while in the NHL no less than 18 teams managed to reach the last act of the competition. Making a brief comparison between the two leagues, we can see strictly from these graphs, that from a professional point of view, the NHL is much more competitive than the NBA, with the hard salary cap having a more beneficial effect on the competition compared to the NBA soft salary cap. Obtaining the champion trophy in any professional league in the world is the dream come true for any professional player. By comparing the possibilities that the NHL offers compared 
to the possibilities that the NBA offers, according to the graphs above, we can identify a better possibility for NHL players to reach the final and win the much-desired trophies. From this point of view, a hard salary cap is a plus compared to a soft salary cap and luxury tax.

\subsection{Regression analysis}

For better, more accurate, and valuable results, a simple regression was also tested and summarized in Figure 5. This regression helps us test, whether there is a direct relation or not between the variables in our analysis.

Model I Model II

\begin{tabular}{lcccc} 
Variable & Coefficient & Std. error & Coefficient & Std. error \\
\hline Const & $26.89 * * *$ & 1.7 & $33.99^{* * *}$ & 2.24 \\
Use of salary & $-10.78^{* * *}$ & 1.57 & $-15.88^{* * *}$ & 1.92 \\
Hard Cap & & & $-3.43^{* * *}$ & 0.75
\end{tabular}

YEAR NO NO

\begin{tabular}{lcc}
$\mathrm{N}$ & 781 & 781 \\
Adj.R2 & $\mathbf{5 \%}$ & $\mathbf{8 \%}$ \\
\hline
\end{tabular}

Figure 5. Hard cap regression, Model I \& Model II

Source: authors

Figure 5 regression presents the relationship between placing and usage of the salary cap in the professional leagues from North America. The analyzed models present in a clear way the use of the salary cap that directly influences the economic and professional management of the organizations in the associations, through economic factors. More importantly, the role of the salary cap directly influences the ranking of North American professional leagues, because at a glance we can say that the NHL, which has a hard salary cap, compared to the NBA, which has a soft salary cap, manages to maintain a more competitive league with a much lower chance of winning for organizations with high economic power which offers fans, an extra reason to watch the championship matches.

Model III $\quad$ Model IV

\begin{tabular}{lcccc} 
Variable & Coefficient & Std. error & Coefficient & Std. error \\
\hline Const & $35.23^{* * *}$ & 2.85 & $35.05^{* * *}$ & 3.75 \\
Use of salary & $-15.61 * * *$ & 1.89 & $-16.20^{* * *}$ & 1.9 \\
Hard Cap & $-3.50^{* * *}$ & 0.70 & $-3.57 * * *$ & 0.76 \\
Salary Cap & -0.161 & 0.229 & -0.135 & 0.579 \\
& & & & \\
YEAR & NO & & YES &
\end{tabular}

$\mathrm{N}$

781

781

Adj.R2 $8 \%$ $\mathbf{7 \%}$

Note: $* * * \mathrm{p}<0.0001 ; \mathrm{P}<0.05 ; * \mathrm{p}<0.2 ;$ Dependend variable placing

Figure 6. Hard cap regression, Model III \& Model IV

Source: authors

The results in Figure 5 shows that salary cap when used in itself does not predict team standings in addition to the usage of the salary cap and the type of the salary cap, as the coefficient for this variable is not statistically significant in both models. More importantly, the amount of salary cap and the 
addition of the luxury tax did not alter the results from models I and II, both variables use of salary and hard cap remained statistically significant at $1 \%$ while the size of coefficients remained virtually the same.

Therefore, the empirical results show that the type of salary cap has a direct influence on the association and even a slight difference in the types of salary caps (NHL compared with NBA) still could produce a level of competitiveness in the league. As it was expected, the professional league with a hard salary cap appears to be more competitive and more economically stable than a league with a soft salary cap.

\section{CONCLUSIONS}

This research focused on studying the concept of the salary cap model in North America, especially in finding which salary-cap model, hard salary cap or soft salary cap, is capable to provide better competitiveness. It was shown that it's necessary to implement a general salary cap all over the leagues in order to maintain the same level of competitiveness.

Based on the simple regression table, the small competitive advantage for hard salary cap over soft salary cap was presented, based on figures obtained by professional league organizations in North America over the past 13 years. Based on the variables introduced in the regression, it was identified that the impact on the final result was almost non-existent. The biggest impact on the result was the way in which the hard salary cap and the soft salary cap were managed, together with all the exceptions that the organizations had at their disposal to maintain a high level of competitiveness.

Based on the information collected, it turned out that the variation of the finalist teams in the NHL is much higher than in the NBA. 18 out of 31 total teams have managed to reach the final of the competition in the last 13 seasons of the NHL, compared to 10 out of 30 teams in the national basketball league. According to these findings, we can say that from a professional and economic point of view, the NHL manages to train much more elite teams than the NBA, due to the lower salary impact and the way the organizations' budgets and expenses are managed.

For future research, I believe that how an organization establishes its medium and long-term strategies based largely on how it manages its budgets and how it manages to attract new players to give them visibility in the market could be studied. This research could be extended to the economic analysis of the influence of a key player of an organization. Through this, I mention that it is important to see how a key player of the organization can influence the budget, the TV rights that the organization gains, and its visibility in a competitive market.

\section{REFERENCES}

Ajilore, O., \& Hendrickson, J. (2002). The impact of the luxury tax on competitive balance in Major League Baseball. Journal of Sports Economics, 3(2), 3-5

Booth, D. (2007). The field: Truth and fiction in sports history. Routledge.

Cousens, L., \& Slack, T. (2005). Field-level change: The case of North American major league professional sport. Journal of Sport Management, 19(1), 13-42.

Dietl, H. M., Lang, M., \& Werner, S. (2010). The effect of luxury taxes on competitive balance, club profits, and social welfare in sports leagues. International Journal of Sport Finance, 5(1), 41-51.

Dietl, H. M. Franck, E. Lang, M., \& Rathke, A. (2012). Salary cap regulation in professional team sports, 30(3), 307-319.

Kahn, L. M. (2000). The sports business as a labor market laboratory. Journal of Economic Perspectives, 14(3), 75-94.

Larsen, A., Fenn, A. J., \& Spenner, E. L. (2006). The impact of free agency and the salary cap on competitive balance in the National Football League. Journal of Sports Economics, 7(4), 374-390.

Lipasti, A. (2015). Salary Caps in Professional Team Sports - Balancing Competition or Balancing Costs in the National Hockey League?, 116 - 119, https://aaltodoc.aalto.fi/handle/123456789/18311 
NBA salary cap usage (2019-2010), NBA Salary Cap - 2006-2019

Opperman, E. (2017). An Analysis of Sports Markets: Franchise Relocation, League Expansion, and Fan Bases, CMC Senior Theses, Clermont Colleges, https://scholarship.claremont.edu/cmc_theses/1512/.

Siegfried, J., \& Zimbalist, A. (2000). The economics of sports facilities and their communities. Journal of Economic Perspectives, 14(3), 95-114.

Shorin, G. (2017). Team Payroll Versus Performance Professional Sports: Is Increased Spending Associated with Great Success?, Duke University, Durham, North Carolina, https://sites.duke.edu/djepapers/ files/2017/06/grantshorin-dje.pdf.

Thurman, J. S. (2016). Income Inequality in American Professional Sports Leagues. Economics Undergraduate Honors Theses, University of Arkansas, Fayetteville, https://scholarworks.uark.edu/cgi/ viewcontent. cgi? referer $=\&$ httpsredir $=1 \&$ article $=1015 \&$ context $=$ econuht

Vrooman, J. (2000). The economics of American sports leagues. Scottish Journal of Political Economy, 47(4), 364-398. 